\title{
BMJ Open Identifying return to work trajectories among employees on sick leave due to mental health problems using latent class transition analysis
}

\author{
Maitta Spronken (D , , ${ }^{1}$ Evelien P M Brouwers, ${ }^{1}$ Jeroen K Vermunt, ${ }^{2}$ Iris Arends, ${ }^{3}$ \\ Wido G M Oerlemans, ${ }^{4,5}$ Jac J L van der Klink, ${ }^{1}$ Margot C W Joosen ${ }^{1,6}$
}

To cite: Spronken M, Brouwers EPM, Vermunt JK, et al. Identifying return to work trajectories among employees on sick leave due to mental health problems using latent class transition analysis. BMJ Open 2020;10:e032016. doi:10.1136/ bmjopen-2019-032016

- Prepublication history and additional material for this paper are available online. To view these files, please visit the journal online (http://dx.doi. org/10.1136/bmjopen-2019032016).

Received 29 May 2019 Revised 04 December 2019 Accepted 22 January 2020

Check for updates

(c) Author(s) (or their employer(s)) 2020. Re-use permitted under CC BY-NC. No commercial re-use. See rights and permissions. Published by BMJ.

For numbered affiliations see end of article.

Correspondence to Dr Maitta Spronken; maittaspronken@gmail.com

\section{ABSTRACT}

Objectives To develop effective return to work (RTW) interventions for employees on sick leave due to mental health problems (MHPs), a better understanding of individual variation in the RTW process is needed. We investigated which RTW trajectories can be identified among employees with MHPs in terms of RTW duration and relapse occurrence during the RTW process. Additionally, we examined how different RTW trajectories can be described in terms of personal and work characteristics.

Methods Longitudinal sickness absence registry data were collected retrospectively from the largest Dutch occupational health service. Quantitative RTW information as well as personal and work characteristics were extracted. In total, 9517 employees with a sickness absence due to MHPs were included in the analyses (62 938 data points; RTW durations from 29 to 730 days).

Results A latent class transition analysis revealed five distinct RTW trajectories, namely (1) fast RTW with little chance of relapse, (2) slow RTW with little chance of relapse, (3) fast RTW with considerable chance of relapse, (4) slow RTW with considerable chance of relapse and (5) very fast RTW with very small chance of relapse. Differences between employees in the slower and faster trajectories were observed regarding gender, age, type of MHP, organisation sector and organisation size but not regarding part-time work.

Conclusions RTW trajectories among employees with MHPs showed large individual variability and differed on personal and work characteristics. Knowledge on different RTW trajectories and their characteristics contributes to the development of personalised RTW treatments, tailored to specific individuals and organisations.

\section{INTRODUCTION}

Mental health problems (MHPs) pose a major challenge for the labour market. ${ }^{12}$ At any moment, around $20 \%$ of the working-age population suffers from MHPs in the average Organisation for Economic Co-operation and Development country. ${ }^{1-3}$ MHPs include mental illnesses according to psychiatric classification systems (eg, depression) as well
Strengths and limitations of this study

- A unique dataset from the largest Dutch occupational health service was used, including sickness absence data from employees with various demographical backgrounds and mental health problems, working for profit and non-profit organisations of various sizes (9517 employees, 62938 data points).

- The return to work (RTW) process was registered throughout employees' sickness absence period, allowing for a detailed examination of individual variation in RTW trajectories.

- Latent class transition analysis, an innovative and complex data analysis approach, was used to identify distinct trajectories of RTW.

- As our data were originally not gathered for research purposes, information that would be valuable from a research perspective was not always included.

as distress symptoms and burnout. ${ }^{1}$ Apart from the individual burden associated with mental ill health, MHPs result in major economic costs for employers and society at large. In fact, MHPs are generally more costly for society than physical diseases such as cancer and diabetes. ${ }^{4}$ As opposed to physical diseases, the majority of the societal costs $(60 \%-80 \%)$ associated with MHPs are not due to healthcare use but due to increased sickness absence, reduced productivity at work and unemployment. ${ }^{1}$ Therefore, it is highly relevant to study return to work (RTW) in this population. The present article focuses on obtaining a better understanding of individual variation in the RTW process, a topic that has received limited attention in earlier research.

In previous research, predictors of work resumption among employees with MHPs as well as interventions that may enhance RTW have been examined. Results of both types of research vary across studies. One systematic 
review focusing on depression showed strong evidence for a relation between the duration of a depressive episode and work disability (including longer time to RTW), and moderate evidence for associations between the severity of a depressive episode, comorbidity, previous sickness absence and older age and employee's work disability. ${ }^{5}$ Another systematic review focusing on MHPs in general showed strong evidence for a relation between older age and work disability. ${ }^{6}$ In both reviews, evidence was limited or inconclusive for many other factors (eg, gender, education, job type, supervisor behaviour).

Regarding interventions, systematic reviews suggest that medication, enhanced primary care and psychotherapeutic interventions aimed at symptom reduction (eg, cognitive behavioural therapy) do not improve RTW among employees on sick leave due to MHPs. ${ }^{78}$ Psychotherapeutic interventions that include a work-focused component did show encouraging results. ${ }^{9-11}$ While work-focused interventions differ per study and generally consist of multiple components, ${ }^{12}{ }^{13}$ successful interventions appear to combine an early, gradual RTW with work-focused cognitive behavioural and/or problemsolving therapy. ${ }^{12} 14$ Gradual RTW means that employees resume their work step-by-step in terms of work hours and tasks, until they have fully returned to work. Interestingly, interventions that were effective in terms of RTW did not result in larger reductions in psychological complaints compared with control groups. ${ }^{9}{ }^{10}$ Despite some promising findings, interventions with a workfocused component do not always enhance RTW. ${ }^{12}$ 14-17 Hence, knowledge to improve RTW among employees with MHPs is still insufficient.

Previous research has mostly focused on RTW as a 'status' isolated from its course (eg, number of days until full RTW). Moreover, previous studies generally treated employees on sick leave due to MHPs as one homogeneous group. Two studies examined individual variation in trajectories of RTW status. These studies showed large heterogeneity in work disability trajectories among employees with MHPs. ${ }^{18}{ }^{19}$ However, little is known about the RTW process and individual variation in this process. While a gradual RTW seems to be a promising component of successful RTW interventions, the implementation of gradual RTW may vary considerably in practice. Employees may return slower or faster and may relapse during their RTW. ${ }^{12} 2021$

In the present study, we examined which distinct RTW trajectories can be identified among employees on sick leave due to MHPs in terms of RTW duration and relapse occurrence. Additionally, we aimed to provide a description of employees in the different trajectories in terms of personal and work characteristics. A better understanding of different trajectories and their characteristics may allow the development of more effective, personalised RTW interventions. We used a unique dataset from the largest Dutch occupational health service (OHS), including sickness absence data from employees with various demographical backgrounds and MHPs, working for profit and non-profit organisations of various sizes. In most European countries, sick leave information is deduced from a combination of national registry data on disability benefits and self-report measures. In the Netherlands, the gradual RTW process is well registered by OHS, making it an apt setting for examining RTW trajectories.

\section{METHODS \\ Study context}

In the Netherlands, employers have to arrange occupational healthcare for employees within 6 weeks after the start of sick leave. Most employers contract an OHS, an organisation that employs occupational physicians (OPs; qualified medical doctors specialised in occupational health). OPs support employees during their RTW and provide advice to the employer (eg, on necessary work adaptations). The employee and employer make a joint RTW plan within 8 weeks after the start of sick leave, including a potential gradual RTW. For example, an employee may start with $25 \%$ of the contract hours and build up this percentage until reaching a full RTW. The RTW process is registered by the OHS. It may be noted that RTW percentage changes reflect the RTW plan and not consultations with the OP. During the first 2 years of sickness absence, employers are required to compensate minimally $70 \%$ of an employee's preabsence income. The employer cannot fire the employee during this period (see Dutch Gatekeeper Improvement Act). The National Social Security Institute evaluates the RTW process after 2 years of remaining disability. If the employee is considered incapable of working despite sufficient RTW efforts, the contract with the employer ends and the employee starts receiving unemployment benefits from the government.

\section{Patient and public involvement}

This study builds on a large qualitative study focusing on the perspective of patients and other stakeholders. ${ }^{22}$ Furthermore, the study was designed in close collaboration with the OHS. We intend to organise a symposium to share our results with relevant stakeholders.

\section{Study design}

Longitudinal sickness absence data were collected retrospectively from HumanTotalCare, the largest Dutch OHS. Over 80000 companies nationwide contract this OHS, and their registry has RTW data of 1.5 million employees.

\section{Sample population}

Anonymised sickness absence files of employees who were absent due to an MHP in the year 2014 were extracted from the registry of the OHS (15 580 employees). Employees worked in various sectors for companies of varying sizes. For the classification of MHPs, Dutch OPs use a coding system based on the International Classification of Diseases, version 10. Employees with stress complaints (R45), emotional sleeping disorders (F51.9), 
somatoform disorders (F45.0, F45.4, F45.9), adjustment disorders (F43.2, Z73.0), reactions to severe stress (F43.1, F43.9), anxiety disorders (F41.0, F41.1, F40.0, F40.1, F41.9), personality disorders (F60.0, F60.1, F60.2, F60.3, F60.4, F60.6, F60.7, F60.8, F60.9), mood disorders (F30.9, F31.9, F32.9, F34.1, F39), addictions due to psychoactive substances (F10.9, F11.9, F15.9, F19.9), organic psychoses (F09), non-organic psychoses (F20.9, F25.9, F29) and other mental disorders (F48.0, F48.8, F42.9, F44.9, F50.9, F53.9, F63.0, F79, F99) were included. In this coding system, burnout (Z73.0) belongs to the category adjustment disorders.

\section{Data collection}

For each employee on sick leave, the start and end date of the sick leave period, the reporting date and the medical code were indicated in the sickness absence file. Importantly, the RTW percentage at the start of RTW and any changes in the RTW percentage until full RTW (ie, working $100 \%$ of contract hours) were included as well. As employers are generally not responsible anymore for an employee's RTW after 2 years of remaining disability, an absence file usually contained RTW information until a maximum of 2 years. Additional data were extracted on personal and work characteristics, including age, gender, contract hours (ie, work hours per week), sector and organisation size.

\section{Inclusion criteria}

Employees with a sickness absence period from 29 to 730 days (ie, 2years) were selected (13 473 employees). Absences with durations longer than 730 days were deleted as this almost always suggests a registration mistake. For employees who had more than one sickness absence in 2014 (214 employees), the first sickness absence was selected. Furthermore, employees with more than one employer and/or contract (1061 employees) were excluded, as this complicated interpretation. Employees whose contract ended within 7 days after the end of the sickness absence period (1062 employees) were also excluded. For these employees, it was unclear whether they had really returned to work, whether their contract had ended or whether the employer's contract with the OHS had ended. After applying these criteria, 11 350 employees were left in the dataset.

\section{Data cleaning and preparation}

Sickness absence records that contained mistakes were deleted (see online supplementary materials). After data cleaning, the final dataset contained 9517 employees (62 938 data points, ie, RTW percentages, across the sample).

A dataset was created in which the RTW percentage per month was indicated for each employee, until the month of full RTW. If an employee had more than one RTW percentage change during a month, the last RTW percentage was used (this was the RTW percentage that was continued in the next months, until a new RTW percentage change occurred). Furthermore, RTW percentages were recoded into seven categories: $0 \%$, $1 \%-19 \%, 20 \%-39 \%, 40 \%-59 \%, 60 \%-79 \%, 80 \%-99 \%$ and $100 \%$. Next, type of MHP was recoded into four main categories: stress complaints, adjustment disorders, mood disorders and other disorders. Dummy variables were created for the adjustment and mood disorder that occurred most in our dataset, namely burnout and depression. Regarding sector, a distinction was made between profit and non-profit organisations. Dummy variables were created for sectors that were reported more than 500 times in our dataset (industry, wholesale and retail, finance, consultancy, public administration/services, healthcare). Organisation size was recoded into two categories: below 51 employees and above 50 employees.

\section{Statistical analyses}

To identify RTW trajectories, a latent class transition analysis (LCTA) was performed. This analysis allowed the identification of groups of employees showing distinct patterns of RTW (latent classes). We carried out an LCTA as opposed to the more commonly used latent class growth analysis because gradual RTW occurs in stepwise transitions rather than smooth increases. The LCTA consisted of three steps and was carried out in the statistical programme Latent GOLD 5.1 (for more details, see online supplementary materials). ${ }^{23} 24$

In the first step, a latent class transition model was built using the Choice module. RTW percentage category at time t was used as the 'Choice set' (independent variable), and RTW percentage category at time $t+1$ as the 'Choice' (dependent variable). Up and down parameters representing the log odds for making an upward or a downward step, respectively, were modelled separately. These parameters indicated how many RTW percentage categories an employee went upward/downward per gradual RTW step. To determine the optimal number of latent classes, we used the Bayesian Information Criterion (BIC). Additionally, a minimum requirement of $5 \%$ of the total sample size was used for the smallest latent class. ${ }^{25}$ Entropy was reported as a measure of the quality of classification. In the second step, employees were assigned to the different latent classes with a weight that reflected how well each latent class fitted them. ${ }^{26}$ In the third step, the latent classes were compared with respect to their composition in terms of personal and work characteristics using a bias-adjusted three-step approach. ${ }^{27}$ Wald tests were used to determine whether there were significant differences between the latent classes regarding these characteristics $(p<0.05)$. To avoid discarding potentially interesting relations prematurely in these exploratory analyses, no adjustments for the large sample size or multiple testing were made.

\section{RESULTS}

\section{Personal and work characteristics}

Table 1 shows descriptive statistics for personal and work characteristics. There were somewhat more women than 


\begin{tabular}{|c|c|c|}
\hline & M (SD) & Range \\
\hline Age & $41.84(10.75)$ & $16-66$ \\
\hline Contract hours & $33.82(8.09)$ & $1-100$ \\
\hline \multirow[t]{2}{*}{ Number of gradual RTW steps } & $2.35(1.70)$ & $1-18$ \\
\hline & $\mathbf{n}$ & $\%$ \\
\hline \multicolumn{3}{|l|}{ Gender } \\
\hline Male & 4496 & 47.3 \\
\hline Female & 5019 & 52.7 \\
\hline \multicolumn{3}{|l|}{ Type of MHP (four categories) } \\
\hline Stress complaints & 1530 & 16.1 \\
\hline Adjustment disorder & 5470 & 57.6 \\
\hline Mood disorder & 1157 & 12.2 \\
\hline Other & 1333 & 14.1 \\
\hline \multicolumn{3}{|l|}{ Type of MHP (specific) } \\
\hline Burnout & 889 & 9.4 \\
\hline Depressive episode & 1055 & 11.1 \\
\hline \multicolumn{3}{|l|}{ Sector (two categories) } \\
\hline Profit & 6936 & 75.9 \\
\hline Non-profit & 2197 & 24.1 \\
\hline \multicolumn{3}{|l|}{ Sector (specific) } \\
\hline Industry & 1063 & 11.6 \\
\hline Wholesale and retail & 1861 & 20.4 \\
\hline Finance & 560 & 6.1 \\
\hline Consultancy & 1167 & 12.8 \\
\hline Public administration/services & 518 & 5.7 \\
\hline Healthcare & 991 & 10.9 \\
\hline \multicolumn{3}{|l|}{ Organisation size } \\
\hline$\leq 50$ employees & 5022 & 52.8 \\
\hline$>50$ employees & 4495 & 47.2 \\
\hline
\end{tabular}

Age: $n=9516$; hours per week: $n=7534$; gender: $n=9515$; type of MHP: $n=9490$; sector: $n=9133$. For other characteristics, there are no missing data.

The number of gradual RTW steps was calculated by subtracting one from an employee's total number of RTW percentages.

MHP, mental health problem; RTW, return to work.

men in our sample. Furthermore, most employees were diagnosed with an adjustment disorder. The majority of the employees worked in the profit sector, and smaller organisations were somewhat more common than larger organisations. On average, employees resumed their work in two RTW steps.

\section{Identifying RTW trajectories}

LCTAs with one to seven classes were performed (see table 2 for fit statistics). The BIC of the six-class model was slightly lower than the BIC of the five-class model. However, as the sixth class of the six-class model did not meet the minimum requirement of $5 \%$ of the total sample

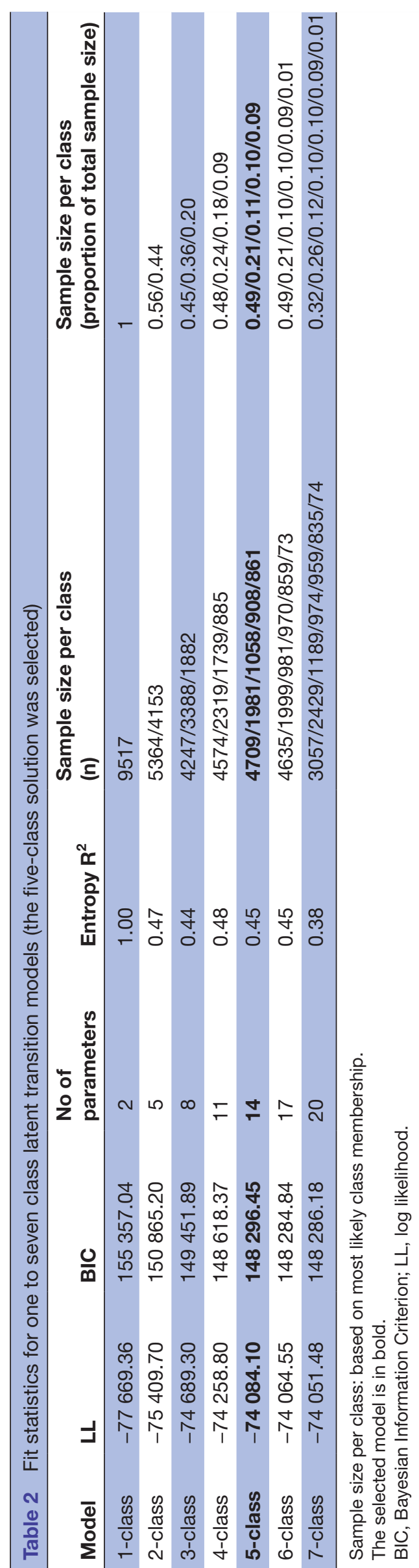


Table 3 Up and down parameter estimates per latent class of the chosen five-class model

\begin{tabular}{|c|c|c|c|c|c|c|c|}
\hline Parameter & $\begin{array}{l}\text { Class } 1 \\
49.5 \% \\
\text { fast RTW } \\
\text { without relapse }\end{array}$ & $\begin{array}{l}\text { Class } 2 \\
20.8 \% \\
\text { slow RTW } \\
\text { without relapse }\end{array}$ & $\begin{array}{l}\text { Class } 3 \\
11.1 \% \\
\text { fast } \mathrm{RTW} \text { with } \\
\text { relapse }\end{array}$ & $\begin{array}{l}\text { Class } 4 \\
9.5 \% \\
\text { slow RTW with } \\
\text { relapse }\end{array}$ & $\begin{array}{l}\text { Class } 5 \\
9.1 \% \\
\text { very fast RTW } \\
\text { without relapse }\end{array}$ & $\begin{array}{l}\text { Wald } \\
\text { statistic }\end{array}$ & $P$ value \\
\hline Up & -0.37 & -1.01 & -0.16 & -0.75 & 7.33 & 5490.74 & $<0.001$ \\
\hline Down & -7.73 & -4.17 & -0.41 & -0.89 & 0.91 & 1045.59 & $<0.001$ \\
\hline
\end{tabular}

Note: Values up parameter coded from 0 to 6 . Values down parameter coded from 0 to 5.

RTW, return to work.

size (this class contained $0.77 \%$ of the total sample size), we selected the five-class solution. The six-class model resulted in the same pattern of findings as the five-class model, except that a small group of employees from the fourth class of the five-class model was assigned to a separate, sixth class. This sixth class differed regarding the degree of relapse during the RTW process but not regarding the general pattern of RTW. The five-class model revealed five distinct, meaningful trajectories of RTW.

Table 3 presents up and down parameters of the fiveclass model. Employees in the first class showed a fast RTW with little chance of relapse during the RTW process (fast RTW without relapse; average of 136 days and 1.96 transitions needed for full RTW). Employees in the second class showed a slow RTW with little chance of relapse (slow RTW without relapse; average of 402 days and 2.47
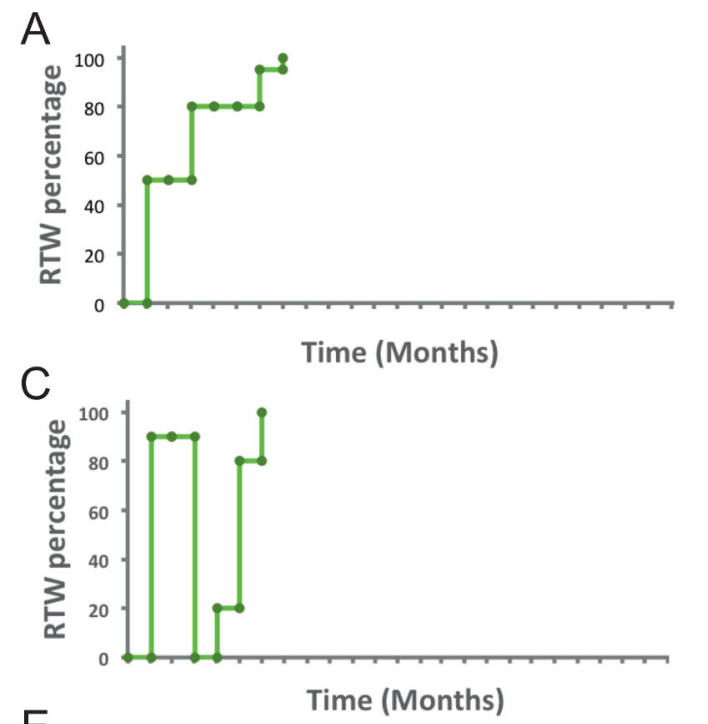

$E$

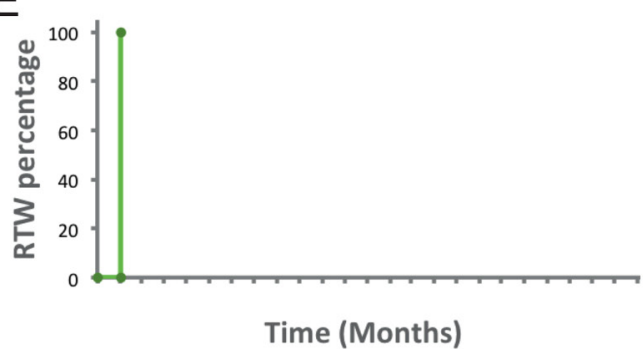

transitions). In the third class, there was a fast RTW with considerable chance of relapse (fast RTW with relapse; average of 194 days and 3.07 transitions). In the fourth class, there was a slow RTW with considerable chance of relapse (slow RTW with relapse; average of 419 days and 3.54 transitions). Employees in the fifth class returned to work very fast and had a very small chance of relapse (very fast RTW without relapse; average of 49 days and 1.00 transitions). Examples of typical trajectories for each latent class are shown in figure 1 (for transition odds per latent class, see online supplementary materials).

\section{Characteristics of RTW trajectories}

We found significant differences between the five trajectories on age, gender, type of MHP, sector and organisation size (all ps $\leq 0.03$ ). No significant differences were revealed for contract hours (see table 4 for means/
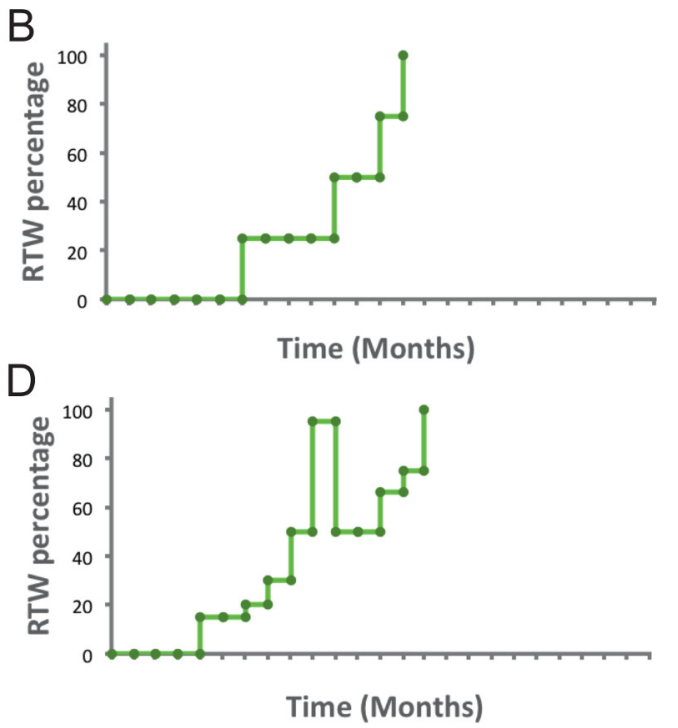

$\begin{array}{ll}\text { A } & \text { Class 1: Fast RTW without relapse } \\ \text { B } & \text { Class 2: Slow RTW without relapse } \\ \text { C } & \text { Class 3: Fast RTW with relapse } \\ \text { D } & \text { Class 4: Slow RTW with relapse } \\ \text { E } & \text { Class 5: Very fast RTW without relapse }\end{array}$ 

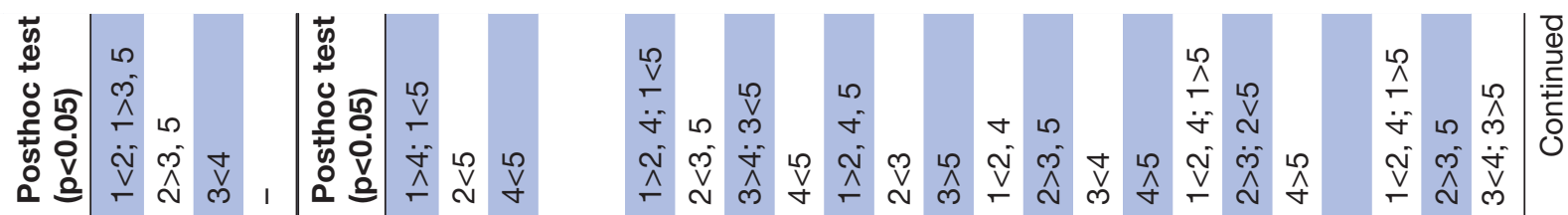

衰文

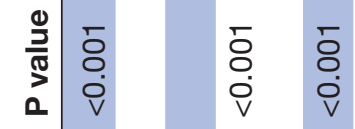

ป

亏ั

ㅎํㅇㅎํำ

흘

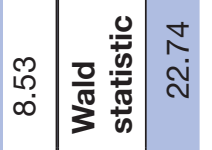

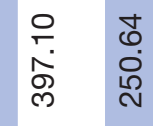

$\underset{\mathfrak{N}}{\stackrel{y}{บ}}$

$\infty$
$\infty$
$\infty$
0
0

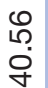

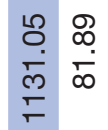
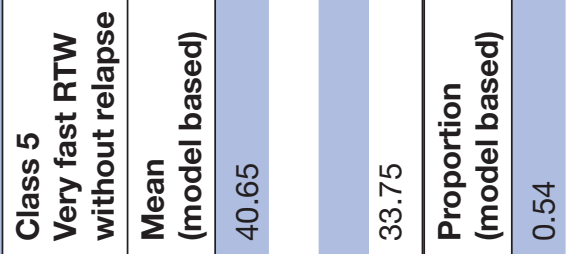

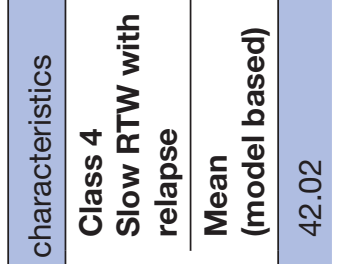

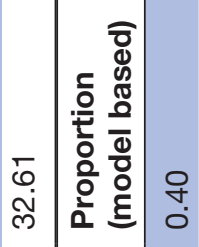

$\hat{\jmath}$

文

웅

웅

둥

$\stackrel{\infty}{\circ}$

एٕ:

సั

$\stackrel{1}{\circ}$

$\stackrel{ }{\circ}$

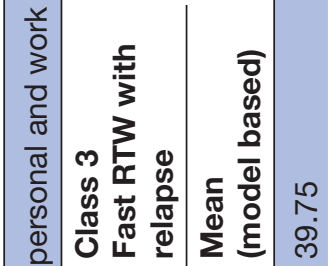

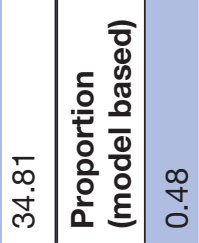

$\frac{0}{\circ}$

ก̊

$\stackrel{\infty}{\circ}$

$\frac{\pi}{\square}$

@ִ

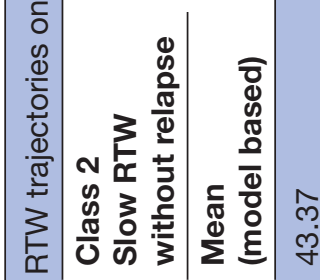

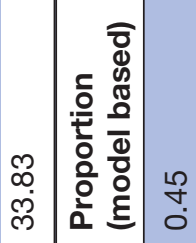

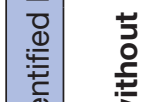

일

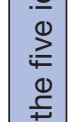

के
0
0
0
0

क品罗 $=\frac{0}{0}$

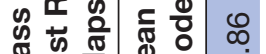

市

옹

חొ

Nָ

$\frac{0}{\circ}$

동

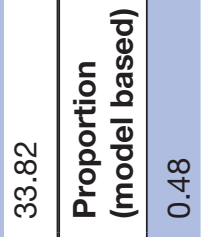

$\stackrel{\infty}{\circ}$

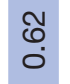

ᄋ̊

$\stackrel{ }{\circ}$

o̊
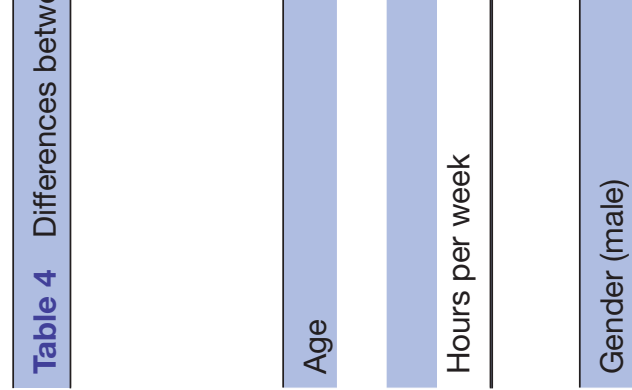

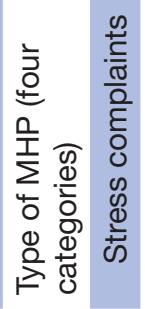
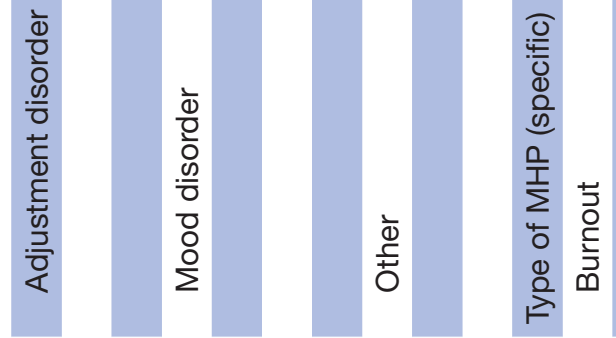

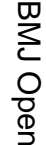

$\stackrel{\vec{p}}{\mathrm{~s}}$

함

\%

$\vec{\circ}$

$\vec{\omega}$

홍.

Nิ

్ㅣ

음

오

N

ग़

กิ

응

흥

잉

$\overrightarrow{\overrightarrow{0}}$

䒜

함

긍.

훙

옹

웅

을.

N

N

श

음

$\stackrel{9}{+}$

웅

高 


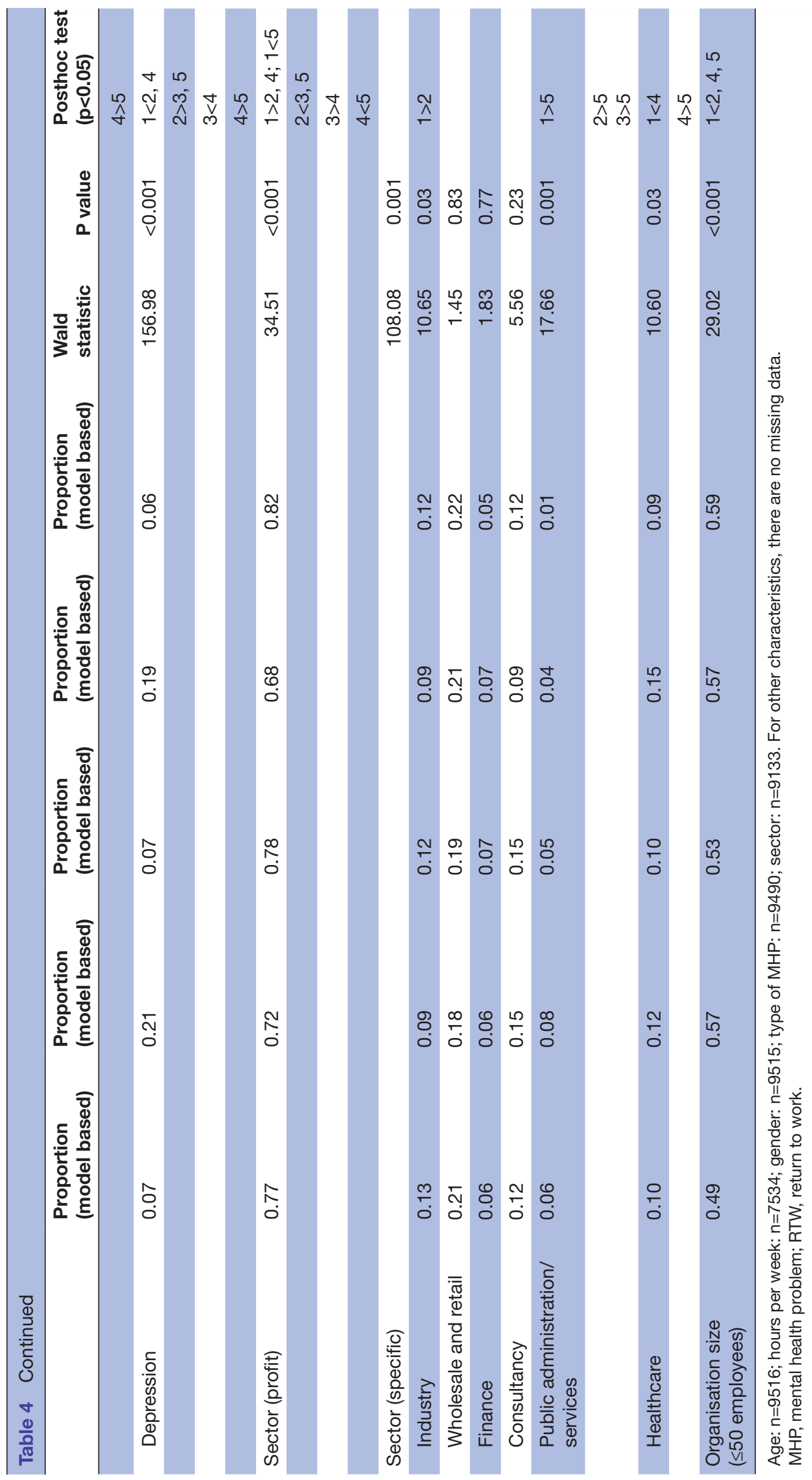

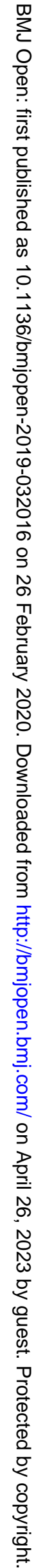


proportions per class and significance tests). The most notable differences are summarised below.

\section{Age}

Employees in the slow trajectories (especially class 2) were on average older compared with employees in the fast trajectories (class 1, 3, 5).

\section{Gender}

The proportion of male employees was higher in the fastest trajectory (class 5) compared with one of the fast (class 1) and both of the slow trajectories (class 2, 4).

\section{Type of MHP}

The fast trajectories (class 1, 3,5) were characterised by more stress complaints compared with the slow trajectories (class 2, 4). Furthermore, the fast trajectories (particularly class 1 ) contained more employees with adjustment disorders than both the slow trajectories (class 2, 4) and the fastest trajectory (class 5). A different pattern was found when examining burnout specifically. The slow trajectories (class 2, 4) were characterised by more employees with burnout than the fast trajectories (class 1, $3,5)$. Finally, employees suffering from mood disorders were more often in the slow trajectories (class 2,4) than in the fast trajectories (class 1,3,5). The same pattern was found for depressive episode.

\section{Sector}

The fast trajectories (class 1, 3, 5) contained more employees working in the profit sector compared with the slow trajectories (class 2, 4). When examining sectors that were reported more than 500 times, differences between the trajectories were found for industry, public administration/services and healthcare, but not for wholesale and retail, finance and consultancy. The proportion of employees from industry was higher in the fast trajectory without relapse (class 1) compared with the slow trajectory without relapse (class 2). Furthermore, the proportion of employees working in public administration/services was lower in the fastest trajectory (class 5) compared with most other trajectories (class 1, 2, 3). The proportion of employees from the healthcare sector was higher in the slow trajectory with relapse (class 4 ) compared with the fast trajectories without relapse (class 1, 5).

\section{Organisation size}

The proportion of employees who worked in small organisations was lower in the fast RTW without relapse trajectory (class 1) compared with the slow trajectories (class 2, 4 ) and the fastest trajectory (class 5).

\section{DISCUSSION}

\section{Summary}

We identified five distinct RTW trajectories, namely (1) fast RTW with little chance of relapse, (2) slow RTW with little chance of relapse, (3) fast RTW with considerable chance of relapse, (4) slow RTW with considerable chance of relapse and (5) very fast RTW with very small chance of relapse. Stress complaints and adjustment disorders were more prevalent in the faster trajectories, while depression and burnout specifically were more prevalent in the slower trajectories. Furthermore, older employees, women and non-profit sector employees showed longer trajectories. Interestingly, part-time employees did not resume work faster than full-time employees. Individual variation in the RTW process among employees with MHPs has received limited attention in earlier research.

\section{Individual variation in RTW}

The identified trajectories varied on RTW duration and relapse occurrence. Around $60 \%$ of employees fully resumed work within approximately 6 months (class 1 , 3 ), around $30 \%$ of employees within approximately 14 months (class 2, 4) and around $10 \%$ of employees within $1 / 2$ months (class 5). About $20 \%$ of employees relapsed during the RTW process (class 3, 4). This finding is in line with earlier studies reporting that relapse is common after a partial RTW. ${ }^{12} 2021$ In the short term, faster trajectories without relapse may be most beneficial, especially from an employer perspective. However, slower trajectories with an early onset but a slow RTW process in terms of gradual RTW percentage increases may be more beneficial for certain employees in the long term (eg, employees with more severe MHPs or disadvantageous circumstances at home or at work).

The observed differences between employees in the slower and faster trajectories on personal and work characteristics provide some insight regarding which employees may resume work slowly and what different employees may need in terms of RTW support. Significant statistical differences between trajectories were found for most characteristics. Because of the large sample size, we had a high-powered study, allowing us to detect both smaller and larger differences between trajectories. Especially differences regarding type of MHP seemed clinically relevant. The proportion of employees with stress complaints was higher in the faster trajectories, while the proportion of employees with a mood disorder was higher in the slower trajectories. Previous research also showed some evidence for a relation between depression and longer work disability duration. ${ }^{6}$ Furthermore, the proportion of employees with adjustment disorders was higher in the faster trajectories, while the proportion of employees with burnout was higher in the slower trajectories. Work stress models suggest that (chronic) stress may eventually result in more severe MHPs such as burnout and depression. ${ }^{28}$ Early intervention for employees with stress complaints and adaptation disorders may prevent more severe complaints and prolonged RTW trajectories.

Regarding other characteristics, employees in the slower trajectories were on average older. This finding is consistent with previous research. ${ }^{56}$ Furthermore, male employees and profit sector employees were more often in faster trajectories. The differences between men and women may partly be explained by job differences. For 
instance, more women work in the healthcare sector, where realising suitable work adaptations may be relatively challenging. Earlier reviews showed limited/inconclusive evidence for relations between gender or sector and work disability ${ }^{56}$ Interestingly, part-time employment was not associated with faster work resumption than fulltime employment. An explanation may be that people generally work part time for a reason (eg, child care). It may be noted that age, gender and type of MHP are likely to be related. Hence, differences between RTW trajectories in terms of MHPs may partly be explained by differences in age and/or gender.

Interestingly, no differences on personal and work characteristics were observed when comparing trajectories with and without relapse. The finding that these trajectories did not differ on demographical factors, type of MHP or work context characteristics suggests that differences between trajectories with and without relapse may be explained by psychological and human work-related factors (eg, supervisor behaviour, sense of control, general working conditions). ${ }^{29-32}$ Importantly, this would imply that relapse depends on factors that can be influenced to a certain extent.

\section{Strengths and limitations of this study}

We used a unique sickness absence dataset from the largest Dutch OHS. Hence, a major strength was the large sample, including employees with various demographical backgrounds, MHPs and work environments. Gradual RTW percentages were registered throughout employees' sickness absence period, allowing for a detailed examination of individual variation in the RTW process. Latent class transition analysis, an innovative and complex data analysis approach, was used to identify distinct trajectories of RTW. Latent class transition analysis is more suitable for data with stepwise changes than the more common latent class growth analysis.

While our data were a rich source of information on the RTW process, these data were not gathered for research purposes. Therefore, information that would be valuable from a research perspective was not always included. For instance, it is unknown whether employees were on sick leave before, there was no information on comorbidity, relevant psychological variables (eg, self-efficacy) ${ }^{33}$ were not measured, and it is unknown whether employees participated in interventions during their RTW. Another limitation of our study was that employees with temporary contracts had to be excluded if their contract ended during the sickness absence. Furthermore, OPs generally reported the broader category of a MHP (eg, adjustment disorder) but not always a specific diagnosis (eg, burnout). Finally, it is possible that data deviated from reality at times (eg, an employee's RTW percentage may not have been adapted immediately after a partial RTW) and that information on work characteristics was not always up to date.

\section{Future research and conclusion}

Future research may investigate whether OPs recognise the different RTW trajectories and how knowledge about different trajectories affects treatment decisions (eg, using focus groups). Since no differences between trajectories with and without relapse were found on the characteristics included in this study, future studies may examine whether trajectories differ on psychological and human work-related characteristics such as RTW selfefficacy, ${ }^{33}$ experienced autonomy over the RTW process, ${ }^{29}$ frequency and timing of communication between different stakeholders ${ }^{30} 31$ and psychosocial work environment. ${ }^{32}$ To study this, it is highly relevant for OHS to start recording these factors systematically in collaboration with researchers. Future research may also relate different trajectories to sustainable work resumption, productivity and well-being. This may reveal whether certain trajectories are disadvantageous for some employees in the long term.

In conclusion, using data from the largest Dutch OHS, we found significant heterogeneity in RTW trajectories among employees with MHPs. Early support for employees with stress complaints and adaptation disorders may prevent more severe complaints and prolonged trajectories. The finding that trajectories with and without relapse did not differ on demographical factors, type of MHP and work context characteristics suggests that differences between employees in these trajectories may be explained by (potentially modifiable) psychological and human work-related factors. Knowledge on different RTW trajectories and their characteristics contributes to the development of personalised RTW treatments, tailored to specific individuals and organisations.

\section{Author affiliations}

${ }^{1}$ Tranzo Scientific Center for Care and Wellbeing, Tilburg School of Social and Behavioral Sciences, Tilburg University, Tilburg, The Netherlands

${ }^{2}$ Department of Methodology and Statistics, Tilburg School of Social and Behavioral Sciences, Tilburg University, Tilburg, The Netherlands

${ }^{3}$ Department of Health Sciences, Community and Occupational Medicine, University Medical Center Groningen, Groningen, The Netherlands

${ }^{4}$ Research and Business Development, HumanTotalCare, Utrecht, The Netherlands ${ }^{5}$ Organisational Dynamics, Erasmus University Rotterdam, Rotterdam, The Netherlands

${ }^{6}$ Department Human Resource Studies, Tilburg School of Social and Behavioral Sciences, Tilburg University, Tilburg, The Netherlands

Acknowledgements We would like to thank the Institution of Occupational Safety and Health (IOSH) for funding this research. Furthermore, we would like to thank our collaborators from HumanTotalCare for sharing this large and unique dataset with us. In particular, we would like to thank Niels Verlage for the data extraction and his insightful comments and suggestions.

Contributors IA wrote the grant proposal for this project, together with EPMB, MCWJ and JJLvdK. MS carried out the project in close collaboration with MCWJ and EPMB. She developed the study design further, carried out the data preparation and analysis and wrote the manuscript. WGMO provided context to the data throughout the different research phases. JKV developed the data analysis plan and was closely involved in carrying out the analysis. All authors contributed to the interpretation of the results, provided feedback on the manuscript and approved the final manuscript.

Funding This work was supported by the IOSH (grant number: R/1626/2).

Competing interests WGMO worked for the occupational health service (HumanTotalCare) that gathered the data used in this article. He was not involved in the analyses of the data.

Patient consent for publication Not required. 
Ethics approval Ethical approval for this study was obtained from the Ethics Review Board of the School of Social and Behavioral Sciences of Tilburg University (reference: EC-2017.EX132)

Provenance and peer review Not commissioned; externally peer reviewed.

Data availability statement No data are available. The authors do not have consent from the occupational health service to share the data used in this project. Specific questions regarding the data and data analysis can be directed at the first author of this manuscript.

Open access This is an open access article distributed in accordance with the Creative Commons Attribution Non Commercial (CC BY-NC 4.0) license, which permits others to distribute, remix, adapt, build upon this work non-commercially, and license their derivative works on different terms, provided the original work is properly cited, appropriate credit is given, any changes made indicated, and the use is non-commercial. See: http://creativecommons.org/licenses/by-nc/4.0/.

ORCID iD

Maitta Spronken http://orcid.org/0000-0002-4390-9586

\section{REFERENCES}

1 OECD. Sick on the job? Myths and realities about mental health and work [Internet]. Mental Health and Work, OECD Publishing, 2012. Available: http://dx.doi.org/10.1787/9789264124523-en

2 OECD. Fit mind, fit job: From evidence to practice in mental health and work [Internet]. Paris: Mental Health and Work, OECD Publishing, 2015. Available: http://www.oecd-ilibrary.org/ employment/fit-mind-fit-job_9789264228283-en

3 Eaton WW, Martins SS, Nestadt G, et al. The burden of mental disorders. Epidemiol Rev 2008;30:1-14.

4 Trautmann S, Rehm J, Wittchen $\mathrm{H}$. The economic costs of mental disorders. Do our societies react appropriately to the burden of mental disorders? EMBO reports, EMBO Press, 2016. Available: https://www.embopress.org/doi/full/10.15252/embr.201642951

5 Lagerveld SE, Bültmann U, Franche RL, et al. Factors associated with work participation and work functioning in depressed workers: a systematic review. J Occup Rehabil 2010;20:275-92.

6 Cornelius LR, van der Klink JJL, Groothoff JW, et al. Prognostic factors of long term disability due to mental disorders: a systematic review. J Occup Rehabil 2011;21:259-74.

7 Nieuwenhuijsen K, Faber B, Verbeek JH, et al. Interventions to improve occupational health in depressed people (review). Cochrane Database Syst Rev 2014;12:1-140.

8 Arends I, Bruinvels DJ, Rebergen DS, et al. Interventions to facilitate return to work in adults with adjustment disorders. Cochrane Database Syst Rev 2012;12.

9 der KJJLV, Blonk RWB, Schene AH, et al. Reducing long term sickness absence by an activating intervention in adjustment disorders: a cluster randomised controlled design 2003;60:429-37.

10 Blonk RWB, Brenninkmeijer V, Lagerveld SE, et al. Return to work: a comparison of two cognitive behavioural interventions in cases of work-related psychological complaints among the self-employed. Work Stress 2006;20:129-44.

11 Lagerveld SE, Blonk RWB, Brenninkmeijer V, et al. Workfocused treatment of common mental disorders and return to work: a comparative outcome study. J Occup Health Psychol 2012;17:220-34.

12 Nigatu YT, Liu Y, Uppal M, et al. Interventions for enhancing return to work in individuals with a common mental illness: systematic review and meta-analysis of randomized controlled trials. Psychol Med 2016;46:3263-74.

13 Dewa CS, Loong D, Bonato S, et al. The effectiveness of return-towork interventions that incorporate work-focused problem-solving skills for workers with sickness absences related to mental disorders: a systematic literature review. BMJ Open 2015;5:14.
14 Bouman S, Van Ede S, De Jong P, et al. Werken met psychische klachten - op zoek naar 'good practices.' Den Haag 2015.

15 Noordik E, van der Klink JJ, Geskus RB, et al. Effectiveness of an exposure-based return-to-work program for workers on sick leave due to common mental disorders: a cluster-randomized controlled trial. Scand J Work Environ Health 2013;39:144-54.

16 Martin MHT, Nielsen MBD, Madsen IEH, et al. Effectiveness of a coordinated and tailored return-to-work intervention for sickness absence beneficiaries with mental health problems. J Occup Rehabil 2013;23:621-30.

17 Brouwers EPM, Tiemens BG, Terluin B, et al. Effectiveness of an intervention to reduce sickness absence in patients with emotional distress or minor mental disorders: a randomized controlled effectiveness trial. Gen Hosp Psychiatry 2006;28:223-9.

18 Hellström L, Madsen T, Nordentoft M, et al. Trajectories of return to work among people on sick leave with mood or anxiety disorders: secondary analysis from a randomized controlled trial. J Occup Rehabil 2017:1-12.

19 Farrants K, Friberg E, Sjölund S, et al. Work disability trajectories among individuals with a sick-leave spell due to depressive episode $\geq 21$ days: a prospective cohort study with 13-month follow up. $J$ Occup Rehabil 2018;28:678-90.

20 Koopmans PC, Bültmann U, Roelen CAM, et al. Recurrence of sickness absence due to common mental disorders. Int Arch Occup Environ Health 2011;84:193-201.

21 Virtanen M, Kawachi I, Oksanen T, et al. Socio-economic differences in long-term psychiatric work disability: prospective cohort study of onset, recovery and recurrence. Occup Environ Med 2011;68:791-8.

22 Joosen MCW, Arends I, Lugtenberg M, et al. Barriers to and facilitators of return to work after sick leave in workers with common mental disorders: perspectives of workers, mental health professionals, occupational health professionals, general physicians and managers. Leicestershire, UK: report IOSH; October 20172017.

23 Vermunt JK, Magidson J. Latent GOLD 4.0 user's guide. Belmont, MA: Statistical Innovations Inc, 2005

24 Vermunt JK, Magidson J. Latent GOLD 5.0 upgrade manual. Belmont, MA: Statistical Innovations Inc, 2013.

25 Nasserinejad K, van Rosmalen J, de Kort W, et al. Comparison of criteria for choosing the number of classes in Bayesian finite mixture models. PLoS One 2017;12:1-23.

26 Vermunt JK, Magidson J. Technical guide for latent GOLD 5.0: basic, advanced, and syntax. Belmont, MA: Statistical Innovations Inc, 2013.

27 Bakk Z, Tekle FB, Vermunt JK. Estimating the association between latent class membership and external variables using biasadjusted three-step approaches. In: Sociological methodology. , 2013: 43, 272-311.

28 Schaufeli WB, Bakker AB. Job demands, job resources, and their relationship with burnout and engagement: a multi-sample study. $J$ Organ Behav 2004;25:293-315.

29 Farholm A, Halvari H, Niemiec CP, et al. Changes in return to work among patients in vocational rehabilitation: a self-determination theory perspective. Disabil Rehabil 2017;39:2039-46.

30 Russell E, Kosny A. Communication and collaboration among returnto-work stakeholders. Disabil Rehabil 2018;17:1-10.

31 Nieuwenhuijsen K, Verbeek JH, de Boer AG, et al. Supervisory behaviour as a predictor of return to work in employees absent from work due to mental health problems. Occup Environ Med 2004:61:817-23.

32 Andrea H, Beurskens AJ, Metsemakers JF, et al. Health problems and psychosocial work environment as predictors of long term sickness absence in employees who visited the occupational physician and/or general practitioner in relation to work: a prospective study. Occup Environ Med 2003;60:295-300.

33 Lagerveld SE, Blonk RWB, Brenninkmeijer V, et al. Return to work among employees with mental health problems: development and validation of a self-efficacy questionnaire. Work Stress 2010;24:359-75. 